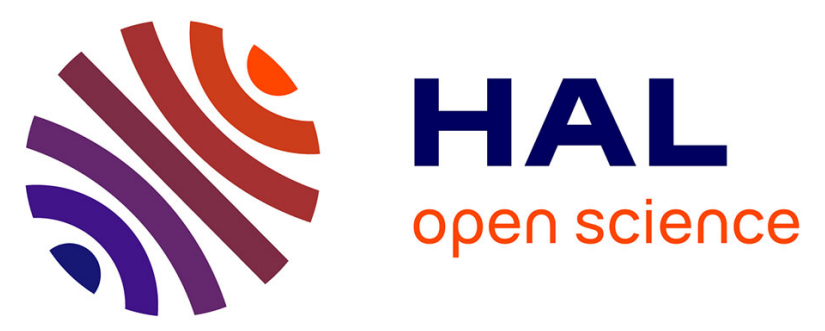

\title{
Brain activity reflects (chronic) welfare state: evidence from individual electroencephalography profiles in an animal model
}

Mathilde Stomp, Serenella D'ingeo, Severine Henry, Hugo Cousillas, Martine Hausberger

\section{To cite this version:}

Mathilde Stomp, Serenella D'ingeo, Severine Henry, Hugo Cousillas, Martine Hausberger. Brain activity reflects (chronic) welfare state: evidence from individual electroencephalography profiles in an animal model. Applied Animal Behaviour Science, 2021, 236, pp.105271. 10.1016/j.applanim.2021.105271 . hal-03146763

HAL Id: hal-03146763

https://hal-univ-rennes1.archives-ouvertes.fr/hal-03146763

Submitted on 16 Jun 2021

HAL is a multi-disciplinary open access archive for the deposit and dissemination of scientific research documents, whether they are published or not. The documents may come from teaching and research institutions in France or abroad, or from public or private research centers.
L'archive ouverte pluridisciplinaire HAL, est destinée au dépôt et à la diffusion de documents scientifiques de niveau recherche, publiés ou non, émanant des établissements d'enseignement et de recherche français ou étrangers, des laboratoires publics ou privés. 


\title{
Brain activity reflects (chronic) welfare state: evidence from
}

\section{individual electroencephalography profiles in an animal model}

\author{
Stomp M..$^{{ }^{*}}$, d'Ingeo S. ${ }^{1,2}$, Henry S. ${ }^{1}$, Cousillas H. ${ }^{1}$, Hausberger M ${ }^{1}$
}

${ }^{1}$ Univ Rennes, CNRS, Normandie Univ, EthoS (Éthologie animale et humaine) - UMR 6552, F-35380 Paimpont, France

${ }^{2}$ Department of Veterinary Medicine, Section of Behavioral Sciences and Animal Bioethics, University of Bari “Aldo Moro", Bari, Italy

*corresponding author: mathilde.stomp@hotmail.fr

\section{Highlights}

- Individual EEG profiles are associated with different welfare scores.

- Horses in a good welfare state produce less gamma waves in the right hemisphere.

- Theta waves production is correlated to stereotypic behaviours performance.

- Resting state EEG appears as a reliable tool for assessing animal welfare. 


\begin{abstract}
Assessing the animal welfare state is a challenge given the subjective individual cognitive and emotional processing involved. Electroencephalography (EEG) spectrum analysis has proved an ecologically valid recording situation to assess the link between brain processes and affective or cognitive states in humans: a higher slow wave/fast wave ratio has been associated with a positive internal state. In particular, a high production of theta power $(3-8 \mathrm{~Hz})$ has been related to positive emotions. On the other hand, it has been hypothesized that a left hemisphere (LH) dominance may be associated with a better welfare state. Here, we test the hypothesis that individual differences in the resting-state quantitative EEG power spectrum of adult horses $(\mathrm{N}=18)$ and its lateralization pattern may reflect individual subjective perception of their conditions of life and welfare state. The results show clear individual differences in the proportions of the different waves and their inter-hemispheric distribution. Three different EEG power spectrum profiles were highlighted, from a bilateral predominance of theta waves in horses in a more positive welfare state to a bilateral predominance of beta waves in horses with clear expressions of compromised welfare. Interestingly, particular correlations were found between wave power activity and welfare parameters. We found a negative correlation between the number of stereotypic behaviours per hour and the median proportion of theta waves in the left hemisphere. and between the overall state (total chronic stress score) of welfare and gamma production in the right hemisphere $(\mathrm{RH})$. These findings go along the hypothesis of a particular involvement of the left hemisphere for positive processing and of the right hemisphere for negative processing. However, the pattern of laterality did not appear as the most important
\end{abstract}


feature here as both extreme clusters in terms of welfare showed bilateral predominance of one wave type. It is possible that hemispheric specialization makes more sense during acute emotion-inducing conditions rather than in this resting-state context (i.e. in absence of any high emotion-inducing stimulation), although the opposition gamma versus theta waves between both hemispheres in the horses with an intermediate welfare state is noticeable and intriguing. It seems that bilateral but also LH theta activity is a promising neurophysiological marker of good welfare in horses, while a bilateral or RH high production of gamma waves should alert about potential welfare alterations.

Quantitative resting-state EEG power spectrum appears as a highly promising tool for exploring the brain processes involved in the subjective perception of chronic welfare, as a useful complementary tool for welfare assessment.

Key words: laterality; electroencephalography; theta wave; welfare; horses 


\section{INTRODUCTION}

The animal welfare issue represents one of the major society challenges of the coming years. However, although there are some relatively consensual behavioural indicators (e.g. stereotypic behaviours), their use requires some appropriate training while there is still a need for validation for many others (Hausberger et al., 2020; Lesimple, 2020). As a result, most current indicators correspond to evaluations of compromised welfare (e.g. Broom 1986b; Mason 1991; Boissy et al. 2007). Physiological indicators often lead to contradictory results, as reflected, for instance, by studies on the pituitary-adrenocortical axis activity (Mormède et al., 2007; Pawluski et al., 2017; Rushen, 1991). Overall, behavioural or physiological indicators of a good welfare state are still scarce or at least ambiguous, like the presence of play in adults (Ahloy-Dallaire et al., 2017; Blois-Heulin et al., 2015).

One difficulty is that chronic welfare state is a subjective experience, which means that each individual may be differently affected by the situation (Mendl et al., 2009; Paul et al., 2005). Brain processes appear particularly promising and relevant in regards to affective state and welfare assessment. Indeed, it is well documented in humans that depletion of the neurotransmitter serotonin is thought to be symptomatic of depressed people (Krishnan and Nestler, 2008; Sarrias et al., 1991; Stockmeier, 2003) and Doyle et al. (2011) found that the administration of a serotonin inhibitor (p-Chlorophenylalanine) may induce a pessimistic-like judgement bias in sheep. Similarly, dopamine has been shown to have an impact on belief formation by inducing an optimism bias in humans (Sharot et al., 2012). Central processes are also reflected in measures of the electrical activity of brain: non-invasive electrophysiological 
(Electroencephalography) recordings have shown correlations between the types of waves produced and the internal state in humans. Thus, some authors have proposed that theta waves activity would be correlated to an increase of the parasympathetic and the serotonergic activities (Anderer et al., 2000; Takahashi et al., 2005), suggesting a potential relationship between brain electrophysiological and neuroendocrine activities in regards to affective state. However, there is still a lack of studies regarding the link between cerebral activity and welfare in animals to date. Yet, indirectly, brain lateralization may inform about the cerebral processes involved and different studies converged on the conclusion that stimuli (e.g. visual, auditory) induce different lateralized responses according to their emotional valence (e.g. Davidson 1992). Rogers (2010) for example suggested that animal welfare may be improved by ensuring development of left hemisphere dominance. Electroencephalography (EEG) appears as an additional promising tool for assessing (good/compromised) welfare in animals since it allows to identify both the valence of a behavioural response through lateralized brain activity and its intensity through the wave types produced. Different wave types have been identified from delta waves $(0-3 \mathrm{~Hz})$, characteristic mostly of deep sleep, to gamma waves $(>30 \mathrm{~Hz})$ associated with higher arousal levels, and theta $(3-8 \mathrm{~Hz}$, low arousal), alpha $(8-12 \mathrm{~Hz}$, active awake) and beta $(12-30 \mathrm{~Hz}$, moderate arousal) waves being intermediate. Analysis of the proportions of different wave types produced provides an EEG power spectrum, for which some authors mostly oppose « slow waves » (delta, theta, alpha) and « fast waves » (beta and gamma) (Putman et al., 2010). Indeed, electroencephalography (EEG) spectrum analysis has proved an ecologically valid recording situation to assess the link between brain processes and affective or cognitive states in humans (Sammler et al., 2007). EEG power spectrum analysis thus allows to identify both (1) the emotional valence given to a stimulus by studying the differential activation of the right versus left hemisphere (e.g. Davidson 1995) and (2) its emotional arousal by investigating wave frequency bands proportions produced in response to the given stimulus (Schmidt and Trainor, 
2001). Higher slow waves/fast waves ratios have been linked to greater reward and reduced anxiety-driven affect (Putman et al., 2010): listening to pleasant music or experiencing a "blissful" meditation state are associated with an increase of theta power (3-8 Hz) activity (Aftanas and Golocheikine, 2001; Kabuto et al., 1993; Sammler et al., 2007). Individual differences in brain dynamics are well known (Doppelmayr et al., 1998), and EEG power spectra appear to be influenced by factors such as personality (Inanaga, 1998; Takahashi et al., 2005) or individual cognitive and affective processing of pain (Reddan and Wager, 2019). Since welfare state as "a chronic positive state resulting from the satisfaction of the animal's behavioural and physiological needs and expectations" (e.g. ANSES, 2018) is also influenced by subjective individual cognitive and emotional processing, it could well reflect in restingstate EEG power spectrum. Studies on electrophysiological correlates of chronic welfare are scarce, even almost non-existent, especially in animals, mostly because of technical limitations. Rault and colleagues (2019) recorded cranial epidural EEG wirelessly in pigs during gentle tactile contacts during human-animal interactions. If they highlighted a significant decrease of EEG total power during belly rubbing bouts, however they failed to found any significant difference between contexts regarding delta, theta, alpha, beta and gamma waves. Although promising, this study focused on an acute positive context but did not investigate pigs' chronic welfare state. Therefore further investigations are needed. Most EEG studies performed on animals up to now have aimed at assessing their sleep/awake cycles (Dallaire and Rucklebusch, 1974; Lancel, 1993; Williams et al., 2008) or responses to anaesthesia (D. Williams et al., 2016; D. C. Williams et al., 2016; Williams et al., 2012), using cabled EEG devices which means that animals had to be restrained. Animals had to be shaved in order to get some signal, or, as most usually practiced, electrodes were implanted for intracranial EEG (e.g. Opdam et al. 2002). Consequently, most EEG recordings in animals have been done invasively which induces potential negative memories in the animals (Murrell et al., 2005, 2003) and thus may bias any 
measure of a chronic welfare state. Moreover, such conditions of recordings prevent recordings in field conditions, either because they induce too much constraint (e.g. cabled recordings) or are unacceptable by the animal's owner (e.g. shaving at electrode location). And finally, they do not easily allow to measure a "resting-state" EEG power spectrum, as the animals may find the procedure too invasive, whereas resting-state EEG has proved very useful for measuring chronic states, such as those resulting from chronic pain (de Vries et al., 2013; Meerwijk et al., 2015).

A telemetric EEG recording device, developed recently for horses, has proved useful for measuring brain activity in free-moving animals in their daily life conditions (Cousillas et al., 2017). EEG power spectrum analysis has shown that there was an interaction between the wave types produced and the asymmetry of brain activity in relation with the attentional state of individual horses confronted to a visual stimulus (Cousillas et al., 2017; C. Rochais et al., 2018). In these studies, individual variations were consistent over two different days of recordings. However, there is, for the moment, no information on how the «basal » brain activity of horses may vary according to their chronic welfare state. Different studies have shown that this chronic state may modulate attentional individual characteristics. A strong decrease of attentional engagement or even a total disinterest of animals for their environment, a form of apathy, has been described in animals experiencing chronic stress (sows: Broom 1986; sheep: Fordham et al. 1991; dogs: Beerda et al. 1999) and in horses, lower attentional engagement has been observed in animals experiencing a depressed state or chronic back disorders (Burn et al. 2010, Fureix et al. 2012; Rochais et al. 2016a, b). Clear relationships exist between welfare state and cognition in horses (Hausberger et al., 2019) and thus, one may expect « basal » brain activity to differ according to how animals subjectively assess their daily conditions of life. In the present study, we test the hypothesis that individual differences in the resting-state quantitative EEG power spectrum of adult horses may reflect these individual 
subjective perceptions of their conditions of life and thus their welfare state. We expect that good conditions of life lead to profiles characterized by more slow waves, reflecting a more positive chronic state, as shown in cognitive bias studies (Henry et al., 2017). Restricted living conditions are common in the management of horses, leading to well characterized disorders such as stereotypic behaviours (e.g. Mills 2005a) but also cognitive impairments (Hausberger et al. 2007, Rochais et al. 2016a; review in Hausberger et al. 2019). Here we test, for the first time in animals, whether the welfare state per se may influence the resting-state EEG power spectrum.

\section{METHODS}

\subsection{Ethical Note}

The experiments were carried out in 2017 in accordance with the European Parliament and the European Union Council relative to the animals' protection used for scientific purposes directive 2010/63/UE and complied with the current French laws related to animal experimentation (decree $\mathrm{n}^{\circ} 2013-118$ of 1 February 2013 and its five implementation orders (JO of 7 February 2013), integrated in the Code rural and the Code of the maritime fishing under $\mathrm{n}^{\circ}$ R. 214-87 à R.214-137). According to these European and French laws, our experiment did not require an authorization request. Indeed, our manipulations did not cause any physical or mental pain, they consisted only of a common practice, which is the positioning of a sort of halter on the horse's head that was freely moving in its home environment. Animal husbandry and care were under the management of the recreational horses' owners.

\subsection{Subjects}


The present study was conducted in July 2017 in Brittany (France) on a total of 18 individuals, 7 females, 9 geldings and 2 stallions, from various breeds ( 7 breeds represented, as well as unregistered or mixed-breed horses; $16.6 \%$ of French Saddlebreds) and ages (4 to 21 years old) (Table 1). Horses lived under more or less restricted domestic conditions (2 sites). On each site, only the horses that had been living on the same site and in the same conditions for at least one year have been observed.

In the first site ("Restricted"), nine horses $\left(\mathrm{N}_{\text {mares }}=4, \mathrm{~N}_{\text {geldings }}=5,9\right.$ to 14 years old, $\mathrm{X}$ $+\mathrm{SE}=11.2+1.9$ (various breeds) were living in a riding school, characterized by restricted housing conditions: horses were kept in $3 \times 3 \mathrm{~m}$ individual straw bedded stalls in a barn (with door openings and grids in the wall allowing visual contact with conspecifics), fed industrial pellets twice a day (morning: 9:30; evening: 6:00) and hay (6-7kg) once a day (9am), and were working in riding lessons (including being ridden by riders from beginner to experienced) for 4-12 hours per week under the supervision of a riding teacher. The horses were ridden with typical English riding style (see also (Lesimple et al., 2016, 2010)). Horses went out to paddocks (with grass) every day from one to four hours per day with variable social partners. The second site ("Leisure") included nine recreational horses $\left(\mathrm{N}_{\text {mares }}=3 ; \mathrm{N}_{\text {stallions }}=2 ; \mathrm{N}_{\text {gelding }}=4\right)$ from various ages ( 4 to 21 years old, $\mathrm{X} \pm \mathrm{SE}=13 \pm 6$ ) and breeds. The animals lived under naturalistic conditions: all year long in 1-2 ha pasture with conspecifics, fed grass and hay ad libitum during winter (no industrial pellets) and used for occasional outdoor relaxed leisure riding or no riding $(\mathrm{N}=2)$.

\subsection{Electroencephalography (EEG) recordings \& data analysis}

The horses' electrophysiological activity was recorded using an ambulatory EEG headset (patent \# R23701WO). This headset allows an easy and fast positioning of 5 electrodes on the horse's forehead over the frontal and parietal bones (Cousillas et al., 2017). The electrodes were located on each side of the horse's forehead allowing the recording of the differential activity 
between the most occipital part of the brain and the most frontal one of the left and right hemisphere separately (Cousillas et al., 2017) (Fig.1). The ground electrode was placed on the back of the left ear. For the sake of being as minimally invasive as possible, horses' hairs were not shaved and conductive gel was used between the electrodes and the horses skin. The system was completed by a telemetric EEG recorder made by RF-TRACK (Cesson-Sevigne, France). The EEG amplifier based on a Texas Instruments integrated circuit ADS1294 was connected to a Bluetooth transmitter. The whole telemetric recording setup weighing $110 \mathrm{~g}$ was fixed on the headset. The sampling rate was $250 \mathrm{~Hz}$.

For a week before the beginning of the recordings, horses were trained daily to wear the noninvasive EEG headset (i.e. 5min per day). Horses show rapid changes in attentional shift and changes of state have been shown, in awake horses, around every 3-30 sec. (Fureix et al., 2012b; Rapin et al., 2007; C. Rochais et al., 2018) where horse start changing position, moving head or ears. Therefore, in order to enhance chances to have a reliable measure, we performed 30 sec. recording sessions when the horse was being held in absence of any artificial stimulation (i.e. no visual, auditory or tactile artificial stimulation). During the recordings, all the horses were handled by one of two unfamiliar experimenters (Sd'I or $\mathrm{MH}$ ) who were blind to the welfare assessments. Two EEG recordings sessions took place spaced by two days.

The EEG recordings were processed using a software "EEGReplay4.3" developed by RFTRACK. Before the EEG analysis, the large artifacts due to movements (body, head, ears) were automatically removed, using a smoothly Savitzky Golay function integrated in a homemade software with Python3.6.4 environment, in order to prevent any muscle artifact contamination. The smoothed signal was then subtracted to the raw signal to remove the large low frequency artifacts. To achieve this removing artefact process, the signal variations with amplitudes larger than $200 \mu \mathrm{V}$ were excluded (Kujala et al., 2013). Further examination for the data showed that the maximum good quality recording duration that could be common to all horses (in the same 
behavioural state) was $8 \mathrm{sec}$. Therefore, since there were no significant differences in the EEG profiles between the two sessions $(\mathrm{N}=18$, Left Hemisphere: $42<\mathrm{V}<96,0.10<\mathrm{p}<0.57$; Right Hemisphere: $36<\mathrm{V}<80,0.18<\mathrm{p}<0.89$ ) and intra-individual reliability proved high (see results and Rochais et al. 2018b), we kept for further analysis and inter-individual comparisons the 8 seconds best quality recordings of the first session.

Once the artefacts were removed, the relative EEG power values of delta $(\delta$ : $0-4 \mathrm{~Hz})$, theta $(\theta$ : 4-8 Hz), alpha ( $\alpha: 8-12 \mathrm{~Hz})$, beta $(\beta: 12-30 \mathrm{~Hz})$ and gamma $(\gamma:>30 \mathrm{~Hz})$ frequency bands were extracted (sampling frequency: $250 \mathrm{~Hz}$, i.e. 250 recordings for 1s). Wave percentage values were automatically calculated as the proportion of the mean power values of these 5 wave types (delta, theta, alpha, beta and gamma) both for the right and the left hemisphere independently. Wave frequency proportions data considered for the subsequent analysis correspond to the median proportion of the mean power values extracted over the continuous recording (2000 measures: $8 \mathrm{~s}=(250 \times 0.004 \mathrm{~s}) * 8)$.

EEG profiles were generated based on radar plot representations. Each radius represents the median proportion of each wave in each hemisphere.

\subsection{Welfare assessment \& data analysis}

Our assessment of horses' welfare was similar to that used by Stomp et al. (2018) and was based on an array of validated behavioural (i.e. abnormal repetitive/stereotypic behaviours, grouped here, since there is no evidence of functional differences between both, e.g. Mills 2005a; Lesimple and Hausberger 2014) and postural (i.e. ear positions while feeding) welfare indicators, including the responses of horses during human-horse relationship tests. All observations and tests were performed by the same trained experimenter (M.S.) during week days and during quiet times in the stable or pasture (i.e. outside teaching activities for riding 
school horses). All welfare assessments were performed before the EEG recordings sessions. Data were voice-recorded using a voice-recorder (Sony1ECM-T6) for later analysis.

\section{- Stereotypic behaviours}

Horses' stereotypic behaviour (defined as 'repetitive behaviour induced by frustration, repeated attempts to cope and/or brain dysfunction'; Mason and Rushen 2006) and other abnormal repetitive behaviours are known to increase with inappropriate living conditions (e.g. Mills 2005) and chronic stress (Mason and Rushen, 2006). In horses, most studies converge to show that these behaviours are associated with impaired cognitive (Hausberger et al., 2007; Parker et al., 2008) and reproductive (Benhajali et al., 2014) competencies (review in Hausberger et al. 2019). The prevalence and type of stereotypic behaviours are influenced by feeding (e.g. McGreevy et al. 1995), housing (e.g. Lesimple et al. 2020), social (e.g. Benhajali et al. 2010) and working (e.g. (Hausberger et al., 2009) restrictions. There is no description of such repetitive behaviours in natural conditions (Waring, 2003).

Six 10-min observation sessions (i.e. $60 \mathrm{~min}$ in total per horse) were performed when riding school horses were in their home stall and when leisure horses were in their own pasture. Observations were made during three time periods (twice for each time period): morning (10:00-12:00am), afternoon (2:00-5:00pm) and 30 min before meals (i.e. 9:30am and 6:00pm here, favourable for observing abnormal repetitive movements in restricted conditions (e.g. Mills 2005), but that did not correspond to any particular feeding time for leisure horses). Sampling was on an all-occurrence basis as in Visser et al. (2008), with half of the horses being observed simultaneously, which means that the behaviours concerned were recorded each time they occurred and for each horse. For a behaviour to be considered as SB/ARB, the behavioural sequence had to be repeated at least 3 times successively and observed 5 times, independently of the period of observation (Lesimple et al., 2016). 
Data recorded were the numbers (per hour) of stereotypic behaviours displayed by each individual (see table 2).

\section{- Ear backwards while feeding in stall}

Ears pointing backwards are associated with a horse's acute negative emotional state including pain (for a review: Hausberger et al. 2016) or agonistic interactions (e.g. Waring 2003). Earlier studies have shown that this ear position, when observed during feeding on the ground is also reflective of chronic negative emotional state (Hausberger et al. 2016, Henry et al. 2017). Observations were therefore made in the stables in calm conditions (outside pellet meal times, on a day off work, between 2 and 5 pm, no wind). In order to have homogeneous conditions, the observer recorded ear positions only when the horse showed no reaction (i.e. no change in behaviour) in a single context: the horse was foraging on hay, straw or grass, head down. Four ear positions were defined: forwards, backwards, sidewards and asymmetrical (for details see: e.g. Lesimple et al. 2016). Ear positions while feeding were recorded using instantaneous scan sampling (Altmann, 1974) with a scan every 2 minutes for 30 minutes (i.e. 16 scans). Two sessions, one in the morning, one in the afternoon, were conducted per individual during two consecutive days during quiet hours when all the horses were eating, yielding 64 scans per horse. The percentages of scans including backwards ear positions were calculated for each horse.

- Human-directed behaviours during human-horse relationship tests

Horses' aggressiveness is an indication of a negative chronic state resulting from discomfort or chronic pain (Fureix et al. 2010) and it is used in a variety of welfare and pain scales (reviewed in Hausberger et al. 2016). Social isolation has been shown to lead to aggressive behaviours towards humans at work (Rivera et al., 2002). In order to test individual reactions to humans, 
horses were submitted in their home stalls (for riding school horses), or in the familiar pasture (for recreational horses), to three standardized human-animal relationship tests (e.g. Hausberger et al. 2008) presented in the following order: a sudden approach, repeated five times (e.g. Hausberger and Muller 2002); a motionless person and an approach-contact (e.g. Henry et al. 2005) tests:

- Sudden approach test (Fureix et al., 2009; M. Hausberger \& Muller, 2002; Rochais et al., 2018b): the experimenter, walking slowly along the corridor, appeared suddenly at the top part of the closed door of the box (or the shelter for recreational horses outside) while the horse was feeding (hay, straw). The stalls were equipped with Dutch woodendoors with the top and bottom divided, the bottom being solid and the top with wire grids. The horse's first reaction was assessed as non-aggressive (i.e. looks at the experimenter with upright ears and approaches or does not show any evidence of directed attention toward the experimenter) or aggressive (i.e. looks at the experimenter with backward ears, and/or moves towards the experimenter with ears backward).

- A motionless person test (e.g. Henry et al., 2005): the experimenter entered the box (or the shelter for recreational horses outside) and stood motionless with her back against the closed door, facing inwards and looking at the ground. The test lasted 1 minute. Data recorded were the total number of aggressive behaviours displayed by horses, including threats (threats always included ears backwards and could vary from simple threats, i.e. looking with ears laid back, threats to bite to threatening approaches) and real aggression (bites) (for more details, see (Fureix et al., 2009)).

- An approach-contact test where the experimenter was positioned at $1.5 \mathrm{~m}$ from the subject and approached it perpendicularly, one step per second, up to the neck's level. Then, she tried to touch the horse without forcing the contact. The horse was free to withdraw. The test ended when the experimenter succeeded in stroking the horse at least 
2 s, or after 3 unsuccessful trials. This test was conducted at the right and left horses' sides in a random order (Fureix et al., 2009; Henry et al., 2005).

Data recorded were the total numbers of agonistic behaviours (including ears laid back, threats and attempts to bite) versus positive (approaching with ears forward, sniffing, nibbling) displayed by horses during the three tests (as in (Henry et al., 2017)) and total number of both (i.e. "interactive behaviours" positive+ negative/ human behaviours). However only the number of agonistic behaviours was considered for the total chronic stress score calculation (see below) while the other measures allowed us to compare groups of horses with similar EEG profiles.

\section{- Overall welfare assessment}

We calculated, for each horse, a total chronic stress score (TCSS) adapted from Hausberger et al. (2012) and Henry et al. (2017) reflecting the level of alteration of its chronic welfare state (see also Stomp et al. 2018). TCSS calculation consisted in ranking the horses according to: 1) the number of human-directed aggressive responses during the three human-horse relationships tests, 2) the number of stereotypic behaviours displayed per hour, 3) the percentage of scans with ears backwards while feeding. For all variables, the higher the value, the poorer the welfare state and the higher the rank attributed to the horse. TCSS was then computed by adding up the three calculated ranks for each horse, so that in the end, the higher the horse's TCSS the poorer its welfare. For instance, a horse that ranked 9th lowest according to its number of aggressive responses, 8th lowest according to its number of stereotypic behaviours occurrences and 5th lowest according to its percentage of scans spent with ears backwards while feeding got a TCSS of 22; which was higher, and consequently reflected a poorer welfare, than a TCSS of three obtained by a horse ranked 1st lowest in all variables (see also Stomp et al. 2018).

Two weeks were required to make all the observations. 


\subsection{Statistical analysis}

As data were not normally distributed, we used non-parametric tests (Siegel and Castellan, 1988)

In order to study the intra-individual variability between the two EEG recording sessions, we run Wilcoxon tests (to test for changes between sessions) and Spearman correlation tests (to test for individual consistency in the proportion of waves). A previous study has shown that horses have consistent power profiles over days (Cousillas et al., 2017), and this was confirmed by testing the horses twice. Since there was no difference between both recording sessions ( $N=18$, Left Hemisphere: $42<\mathrm{V}<96,0.10<\mathrm{p}<0.57$; Right Hemisphere: $36<\mathrm{V}<80,0.18<\mathrm{p}<0.89)$ and intra-individual reliability proved high (see results), only recordings from the first session were kept for the subsequent analysis. Spearman's correlation tests, including fdr (i.e. false discovery rate) corrections, were additionally performed to test relationships between wave frequency proportions measured in each hemisphere and the horses' welfare state parameters. Mann Whitney tests were carried out in order to study differences in the proportion of wave frequencies according to sex and age respectively.

In order to understand how welfare state parameters contributed to the wave frequency proportions, a principal component analysis (PCA; (Joliffe, 2002)) was carried out with the data from individuals' EEG recordings using a correlation matrix. Moreover, welfare parameters (i.e. the number of human-directed aggressive responses during the three human-horse relationships tests; the number of stereotypic behaviours displayed in an hour; the percentage of scans with ears backwards while feeding) were additionally considered as illustrative quantitative parameters. The PCA was then inspected and coloured clustered were plotted using a Hierarchical Cluster Analysis (Johnson, 1967). 
Finally, we studied the differences between the three clusters obtained from the Hierarchical Cluster Analysis regarding the different welfare parameters using Kruskall-Wallis tests. Ad hoc multiple comparisons tests (Mann Whitney) were then conducted in case of significance.

All statistics were performed with R v. 3.5.0 (The R foundation for statistical computing, http://www.r-project.org/).

\section{RESULTS}

In accordance with a previous study (Cousillas et al., 2017), we found that the horses had highly consistent individual electroencephalography profiles (i.e. each horse had a similar proportion of waves in each hemisphere between sessions) over time with 11 horses showing high $(\mathrm{r}=0.64$ to $0.74,0.01<\mathrm{p}<0.05)$ and two moderate $(0.52 \leq \mathrm{r} \leq 0.57,0.05<\mathrm{p}<0.06)$ correlations in their individual EEG profiles (proportion of each wave type in each hemisphere) over the two sessions. Only two horses showed a lower correlation. Three horses could not be tested twice for technical reasons. For further analysis and to enhance conformity in measures between horses, only recordings from the first session were thus kept for the subsequent analysis.

The results of the resting-state EEG revealed clear individual differences in the proportions of the different waves and their inter-hemispheric distribution (Fig. 2).

These differences could not be explained by sex (Mann-Whitney tests, $\mathrm{N} 1=$ geldings, $\mathrm{N} 2=$ females, all tests $\mathrm{p}>0.05$ ) nor age (Spearman correlation tests, $\mathrm{N}=18$, all tests $\mathrm{p}>0.05$ ). However, the proportion of theta waves was lower when in horses exhibiting a higher frequency of occurrence of stereotypies $(\mathrm{r}=-0.58, \mathrm{p}=0.05)$. No other significant correlations were found between wave frequency proportions and the other welfare indicators considered separately (aggressive behaviours in HHR tests and ear positions measures) ( $>0.05)$. However, there was a positive correlation at a more global level of welfare assessment: there was a positive 
correlation between the proportion of Gamma waves in the right hemisphere and the total chronic stress score (TCSS) $(\mathrm{r}=0.59, \mathrm{p}=0.04)$ (Fig.3).

It is noticeable however that some of these individual profiles were more similar than others. Therefore, in order to characterize potential resting-state EEG power profile categories, we performed a principal-component analysis followed by a hierarchical cluster analysis, based on the 18 individual horses' EEG recordings. Two dimensions accounted for $72.4 \%$ of the total inertia (variance): dimension 1 separated fast (beta and gamma) and slow (alpha, theta and delta) waves with fast waves being associated with all indicators of compromised welfare, while dimension 2 separated further gamma in the left hemisphere (LH) from the other fast wave proportions and theta in the right hemisphere $(\mathrm{RH})$ from the other slow wave proportions (Fig. $4 a)$.

Three clusters of individuals appeared reflecting differential relative frequencies of fast (gamma, beta) and slow (delta, theta, alpha) waves (Fig. 4b,c). Horses from cluster 1 (N=6) were characterized by low proportions of slow (delta, theta and alpha) and high proportions of fast (beta and gamma) waves in both hemispheres, contrarily to horses from cluster $2(\mathrm{~N}=5)$ which presented slow waves in RH and fast waves (beta and gamma) in LH. Horses from cluster $3(\mathrm{~N}=7)$, presented a high proportion of theta waves in both hemispheres. The three groups differed in terms of relative frequency of waves (Fig. 4d) (Kruskal Wallis test, n1=6, n2=5, n3=7 : delta : $\mathrm{LH} p=0.002, \mathrm{RH}=0.017$; theta $: \mathrm{LH}: \mathrm{p}=0.004, \mathrm{RH}=003$; alpha $: \mathrm{LH} \mathrm{p}=0.006$, RH 0.07 ; beta : LH p=0.03, RH p=0.005; gamma : LH p=0.0006, RH p=0.002). 
Interestingly, all but 2 ( 1 in cluster 1 and 2 respectively) recreational horses, characterized by a « naturalistic » management (stable groups in pastures) and more relaxed type of riding (long reins, low hands) were found in cluster 3 whereas clusters 1 and 2 corresponded mostly to the population of horses kept in more restricted conditions (single stall) and experiencing daily a more tensed type of riding (tight reins, beginners' lessons, e.g. (Lesimple et al., 2010)).

When considering the horses' welfare state, it appeared that there was a tendency for a gradient in TCSS from cluster 1 to cluster 3 (Kruskal Wallis, p=0.07, Fig. 5), mostly related to differences between the management systems (horses in restricted versus recreational conditions: Mann Whitney test, $\mathrm{N}_{\mathrm{L}}=9, \mathrm{~N}_{\mathrm{RS}}=9, \mathrm{~W}=4.5, \mathrm{p}=0.001$ ). Cluster 3 horses performed also more positive behaviours (Mann Whitney $\mathrm{U}$ test $\mathrm{n} 1=7, \mathrm{n} 2=6, \mathrm{U}=3, \mathrm{p}=0.008$, Fig. 5) towards the experimenter in human-horse relationship tests than cluster 2 horses. The time spent in stereotypic behaviours also differed between clusters (Kruskal Wallis, $\mathrm{p}=0.03$, Fig. 5) with no such behaviour observed in cluster 3 . There were less differences between cluster 1 and 2 horses, which, for most of them lived in the same restricted conditions, but they differed in their reactions in the human-horse relationship tests: the cluster 2 horses appeared more indifferent, showing less interactive (negative and positive) behaviours than the cluster 1 horses $(\mathrm{U}=5$, $\mathrm{p}=0.04$ ). There was thus a gradient in the behaviour towards humans, with the cluster 3 horses being the most positive, the cluster 2 horses the most indifferent, and the cluster 1 horses the most aggressive.

The gradient observed in terms of overall chronic stress, in particular stereotypic behaviours and relationship to humans corresponds to a gradient in EEG profiles (Fig. 6), from a bilateral predominance of theta waves in horses in a more positive welfare state to a bilateral 
predominance of beta waves in horses with clear expressions of compromised welfare. Intermediate horses in terms of welfare expression show an interesting axis LH fast (beta and gamma) waves/ RH theta waves (Fig. 6).

\section{DISCUSSION}

This innovative study shows for the first time that horses' welfare state is reflected through their basal electric cerebral activity: quantitative resting-state EEG power profiles did reflect the horses' subjective perception of their conditions of life, hence their subjective welfare state. These results confirm that welfare state is a major factor of modulation of the organism and could explain, for some part, the individual differences observed in previous EEG studies conducted in this species (Cousillas et al., 2017; C. Rochais et al., 2018). Thus, our results support the fact that a chronic stress may durably modify the cerebral activity in horses, reminding the neurochemical changes already known in depressed humans (Krishnan and Nestler, 2008; Sarrias et al., 1991; Stockmeier, 2003). We know that, in horses, chronic stress

may impact the affective state (i.e. higher emotional responses observed in depressed animals when facing a challenging situation or pessimistic cognitive judgment biases) (Fureix et al., 2012, Henry et al. 2017). Our study now shows a potential link between chronic state and cerebral activity: basal bilateral theta production, reflecting a state of calm attention, is related to a good welfare state. Furthermore, these results confirm at the same time that calm attention has to be considered as a reliable indicator of a good welfare state in horses (Rochais et al., 2016b, 2016a). On the other hand, horses that showed clear signs of welfare alteration (i.e. vertebral disorders, stereotypic behaviours) were characterized by an EEG profile mainly composed of gamma waves bilaterally, suggesting a perception bias of the environment for these animals. Indeed, gamma waves are supposed to be related to a negative emotional 
processing (Luo et al., 2007; Oathes et al., 2008) and a high level of cerebral arousal (Rodenbeck et al., 2006).

These results are in concordance with the results in humans showing increased theta production during calm relaxed positive contexts (Aftanas and Golocheikine, 2001; Sammler et al., 2007) and data on horses' welfare showing more calm attention in healthy horses (Ishii et al., 2014; Rochais et al., 2016b), whereas an increase in gamma production has been associated with a high level of alertness (Rodenbeck et al. 2006). This is not the first time that welfare and attentional states have been related one to each other in horses. Indeed, several studies highlighted atypical attention profiles characterized by a lower attentional engagement towards the environment in individuals suffering from back pain (Rochais et al., 2016a) or an unusual gaze fixity in individuals presenting depressive-like symptoms (Fureix et al., 2012b), reminding of results obtain in human studies (Carvalho et al., 2015; Starkstein et al., 1996). Attention is defined as the cognitive ability to focus on a particular stimulus by filtering no relevant stimulations from the environment (Posner et al., 1980), and has been proved to be modulated by the individual internal state in humans (Mendl et al., 2009; Paul et al., 2005). Horses showing welfare alterations present a decrease of cognitive capacities potentially explained by a sensory withdrawal (Hausberger et al., 2019). Our results also converge with the idea that slow waves are more associated with reduced anxiety and greater approach (Putman et al., 2010; Schutter and Van Honk, 2005), as the horses with more theta waves were also more positive towards humans. All in all, the present study confirms the particular importance of the slow/fast waves ratio in regards to the individual internal state assessment (Schutter and Van Honk, 2005, 2004).

The pattern of laterality did not appear as a major feature here as both extreme clusters in terms of welfare showed bilateral predominance of one wave type. It is possible that hemispheric specialization makes more sense during acute emotion-inducing conditions (Sammler et al., 
2007; Vallortigara and Rogers, 2005) rather than in this resting-state context (i.e. in absence of any high emotion-inducing stimulation), although the opposition gamma versus theta waves between both hemispheres in the horses with an intermediate welfare state is noticeable and intriguing. The positive correlation between gamma production in the right hemisphere and the total chronic stress score seem to confirm somewhat the specialization of the right hemisphere for negative processing (Austin and Rogers, 2014; Davidson, 1992; Larose et al., 2006). On the other hand, the negative correlation found between the number of stereotypic behaviours per hour and the median proportion of theta waves in the left hemisphere go along the hypothesis of a particular involvement of the left hemisphere for positive processing (Basile et al., 2009; Davidson, 1992). It seems therefore that bilateral but also LH theta activity is a promising neurophysiological marker of good welfare in horses, while a bilateral or RH high production of gamma waves should alert about potential welfare alterations.

Overall, quantitative resting-state EEG power spectrum appears as a highly promising tool for exploring the brain processes involved in the subjective perception of chronic welfare, as a useful complementary tool for welfare assessment.

The present results constitute an important step forward in the understanding of neurobiological processes related to the welfare state in horses and more broadly in animals. This study opens a novel area of research that can offer a step toward better understanding of animals' mental state and welfare.

\section{AUTHOR DECLARATION}

There are no known conflicts of interest 
Acknowledgments: The authors are grateful to M. S. Gicqueaux and the riding school staff for allowing access to the riding school horses and for their help. Funding: Funding was provided by "le Fonds l'Eperon" and the COST IFCE (Institut Français du Cheval et de l'Equitation: action "Attention et Positivisme"), as well as by Rennes 1 University and CNRS. Author contributions: MS, SH, HC and MH conceived the experiment; MS, SdI, HC, MH performed the experiment, MS, HC analysed the data, MS, SH, HC and $\mathrm{MH}$ wrote the manuscript. Competing interests: the authors declare no competing interests; Data and materials availability: all data may be obtained from the authors under request.

\section{References}

Aftanas, L.I., Golocheikine, S.A., 2001. Human anterior and frontal midline theta and lower alpha reflect emotionally positive state and internalized attention: high-resolution EEG investigation of meditation. Neurosci. Lett. 310, 57-60. https://doi.org/10.1016/S03043940(01)02094-8

Ahloy-Dallaire, J., Espinosa, J., Mason, G., 2017. Play and optimal welfare: Does play indicate the presence of positive affective states? Behav. Processes 156, 3-15. https://doi.org/10.1016/J.BEPROC.2017.11.011

Altmann, J., 1974. Observational study of behavior: sampling methods. Behaviour. https://doi.org/10.2307/4533591

Anderer, P., Saletu, B., Pascual-Marqui, R.D., 2000. Effect of the 5-HT1A partial agonist buspirone on regional brain electrical activity in man: a functional neuroimaging study using lowresolution electromagnetic tomography (LORETA). Psychiatry Res. Neuroimaging 100, 8196. https://doi.org/10.1016/S0925-4927(00)00066-4

Ashley, F.H., Waterman-Pearson, A.E., Whay, H.R., 2005. Behavioural assessment of pain in horses and donkeys: application to clinical practice and future studies. Equine Vet. J. 37, 565-575. https://doi.org/10.2746/042516405775314826

Austin, N.P., Rogers, L.J., 2014. Lateralization of agonistic and vigilance responses in Przewalski horses (Equus przewalskii). Appl. Anim. Behav. Sci. 151, 43-50. https://doi.org/10.1016/J.APPLANIM.2013.11.011

Basile, M., Boivin, S., Boutin, A., Blois-Heulin, C., Hausberger, M., Lemasson, A., 2009. Socially dependent auditory laterality in domestic horses (Equus caballus). Anim. Cogn. 12, 611619. https://doi.org/10.1007/s10071-009-0220-5 
Beerda, B., Schilder, M.B.., Van Hooff, J., De Vries, H.W., Mol, J.A., 1999. Chronic Stress in Dogs Subjected to Social and Spatial Restriction. I. Behavioral Responses. Physiol. Behav. 66, 233-242. https://doi.org/10.1016/S0031-9384(98)00289-3

Benhajali, H., Ezzaouia, M., Lunel, C., Charfi, F., Hausberger, M., 2014. Stereotypic behaviours and mating success in domestic mares. Appl. Anim. Behav. Sci. 153, 36-42. https://doi.org/10.1016/J.APPLANIM.2014.01.002

Benhajali, H., Richard-Yris, M.-A., Ezzaouia, M., Charfi, F., Hausberger, M., 2010. Increasing foraging opportunities welfare and reproduction efficiency in Arab breeding mares, in: 5th European Workshop on Equine Nutrition.

Blois-Heulin, C., Rochais, C., Camus, S., Fureix, C., Lemasson, A., Lunel, C., Bézard, E., Hausberger, M., 2015. Animal welfare: could adult play be a false friend? Anim. Behav. Cogn. 156-185. https://doi.org/10.12966/abc.05.04.2015

Boissy, A., Manteuffel, G., Jensen, M.B., Moe, R.O., Spruijt, B., Keeling, L.J., Winckler, C., Forkman, B., Dimitrov, I., Langbein, J., Bakken, M., Veissier, I., Aubert, A., 2007. Assessment of positive emotions in animals to improve their welfare. Physiol. Behav. 92, 375-397. https://doi.org/10.1016/J.PHYSBEH.2007.02.003

Broom, Donald M., 1986. Indicators of poor welfare. Br. Vet. J. 142, 524-526.

Broom, D.M., 1986. Responsiveness of stall-housed sows. Appl. Anim. Behav. Sci. 15, 186. https://doi.org/10.1016/0168-1591(86)90074-2

Carvalho, N., Laurent, E., Noiret, N., Chopard, G., Haffen, E., Bennabi, D., Vandel, P., 2015. Eye movement in unipolar and bipolar depression: A systematic review of the literature. Front. Psychol. 6, 1809. https://doi.org/10.3389/fpsyg.2015.01809

Cousillas, H., Oger, M., Rochais, C., Pettoello, C., Ménoret, M., Henry, S., Hausberger, M., 2017. An ambulatory electroencephalography system for freely moving horses: an innovating approach. Front. Vet. Sci. 4, 57. https://doi.org/10.3389/fvets.2017.00057

Dallaire, A., Rucklebusch, Y., 1974. Sleep and wakefulness in the housed pony under different dietary conditions. Can. J. Comp. Med. Rev. Can. Med. Comp. 38, 65-71.

Davidson, R.J., 1995. Cerebral asymmetry, emotion, and affective style., in: Davidson, R.J, Hugdahl, K. (Eds.), Brain Asymmetry. Cambridge: MIT Press, pp. 361-387.

Davidson, R.J., 1992. Emotion and Affective Style: Hemispheric Substrates. Psychol. Sci. 3, 39-43. https://doi.org/10.1111/j.1467-9280.1992.tb00254.x

de Vries, M., Wilder-Smith, O.H., Jongsma, M., van den Broeke, E.N., Arns, M., van Goor, H., van Rijn, C.M., 2013. Altered resting state EEG in chronic pancreatitis patients: toward a marker for chronic pain. J. Pain Res. 6, 815-824.

Doppelmayr, M., Klimesch, W., Pachinger, T., Ripper, B., 1998. Individual differences in brain dynamics: Important implications for the calculation of event-related band power. Biol. Cybern. 79, 49-57. https://doi.org/10.1007/s004220050457

Doyle, R.E., Hinch, G.N., Fisher, A.D., Boissy, A., Henshall, J.M., Lee, C., 2011. Administration of serotonin inhibitor p-Chlorophenylalanine induces pessimistic-like judgement bias in sheep. Psychoneuroendocrinology 36, 279-288. https://doi.org/10.1016/j.psyneuen.2010.07.018

Fordham, D.P., Al-Gahtani, S., Durotoye, L.A., Rodway, R.G., 1991. Changes in plasma cortisol and $\beta$-endorphin concentrations and behaviour in sheep subjected to a change of environment. Anim. Prod. 52, 287-296. https://doi.org/10.1017/S0003356100012794 
Fureix, C., Bourjade, M., Henry, S., Sankey, C., Hausberger, M., 2012a. Exploring aggression regulation in managed groups of horses Equus caballus. Appl. Anim. Behav. Sci. 138, $216-$ 228. https://doi.org/10.1016/j.applanim.2012.02.009

Fureix, C., Gorecka-Bruzda, A., Gautier, E., Hausberger, M., 2011. Cooccurrence of Yawning and Stereotypic Behaviour in Horses (Equus caballus). ISRN Zool. 10. https://doi.org/10.5402/2011/271209

Fureix, C., Jego, P., Henry, S., Lansade, L., Hausberger, M., 2012b. Towards an ethological animal model of depression? A study on horses. PLoS One 7, e39280. https://doi.org/10.1371/journal.pone.0039280

Fureix, C., Jego, P., Sankey, C., Hausberger, M., 2009. How horses (Equus caballus) see the world: humans as significant "objects." Anim. Cogn. 12, 643-654. https://doi.org/10.1007/s10071-009-0223-2

Fureix, C., Menguy, H., Hausberger, M., 2010. Partners with bad temper: reject or cure? A study of chronic pain and aggression in horses. PLoS One 5, e12434. https://doi.org/10.1371/journal.pone.0012434

Hafez, E.S.E., 1962. The behaviour of domestic animals., The behaviour of domestic animals. London: Balliere, Tindall \& Cox Ltd.

Hausberger, M., Fureix, C., Bourjade, M., Wessel-Robert, S., Richard-Yris, M.-A., 2012. On the significance of adult play: what does social play tell us about adult horse welfare? https://doi.org/10.1007/s00114-012-0902-8

Hausberger, M., Fureix, C., Lesimple, C., 2016. Detecting horses' sickness: in search of visible signs. Appl. Anim. Behav. Sci. 175, 41-49. https://doi.org/10.1016/J.APPLANIM.2015.09.005

Hausberger, M., Gautier, E., Biquand, V., Lunel, C., Jégo, P., 2009. Could work be a source of behavioural disorders? A Study in horses. PLoS One 4, e7625. https://doi.org/10.1371/journal.pone.0007625

Hausberger, M., Gautier, E., Müller, C., Jego, P., 2007. Lower learning abilities in stereotypic horses. Appl. Anim. Behav. Sci. 107, 299-306. https://doi.org/10.1016/J.APPLANIM.2006.10.003

Hausberger, M., Lerch, N., Guilbaud, E., Stomp, M., Grandgeorge, M., Henry, S., Lesimple, C., 2020. On-farm welfare assessment of horses: The risks of putting the cart before the horse. Animals 10. https://doi.org/10.3390/ani10030371

Hausberger, M., Muller, C., 2002. A brief note on some possible factors involved in the reactions of horses to humans. Appl. Anim. Behav. Sci. 76, 339-344. https://doi.org/10.1016/S01681591(02)00016-3

Hausberger, M., Roche, H., Henry, S., Visser, E.K., 2008. A review of the human-horse relationship. Appl. Anim. Behav. Sci. 109, 1-24.

https://doi.org/10.1016/J.APPLANIM.2007.04.015

Hausberger, M., Stomp, M., Sankey, C., Brajon, S., Lunel, C., Henry, S., 2019. Mutual interactions between cognition and welfare: The horse as an animal model. Neurosci. Biobehav. Rev.

Henry, S., Fureix, C., Rowberry, R., Bateson, M., Hausberger, M., 2017. Do horses with poor welfare show 'pessimistic' cognitive biases? Sci. Nat. 104, 8. https://doi.org/10.1007/s00114-016-1429-1

Henry, S., Hemery, D., Richard, M.-A., Hausberger, M., 2005. Human-mare relationships and 
behaviour of foals toward humans. Appl. Anim. Behav. Sci. 93, 341-362. https://doi.org/10.1016/J.APPLANIM.2005.01.008

Henry, S., Richard-Yris, M.-A., Hausberger, M., 2006. Influence of various early human-foal interferences on subsequent human-foal relationship. Dev. Psychobiol. 48, 712-718. https://doi.org/10.1002/dev.20189

Inanaga, K., 1998. Frontal midline theta rhythm and mental activity. Psychiatry Clin. Neurosci. 52, 555-566. https://doi.org/10.1046/j.1440-1819.1998.00452.x

Ishii, R., Canuet, L., Ishihara, T., Aoki, Y., Ikeda, S., Hata, M., Katsimichas, T., Gunji, A., Takahashi, H., Nakahachi, T., Iwase, M., Takeda, M., 2014. Frontal midline theta rhythm and gamma power changes during focused attention on mental calculation: an MEG beamformer analysis. Front. Hum. Neurosci. 8, 406. https://doi.org/10.3389/fnhum.2014.00406

Johnson, S.C., 1967. Hierarchical clustering schemes. Psychometrika 32, 241-254. https://doi.org/10.1007/BF02289588

Joliffe, I., 2002. Principal component analysis, Second edi. ed. Springer.

Kabuto, M., Kageyama, T., Nitta, H., 1993. EEG power spectrum changes due to listening to pleasant music and their relation to relaxation effects. Nippon Eiseigaku Zasshi 48, 807818.

Krishnan, V., Nestler, E.., 2008. The molecular neurobiology of depression. Nature 455, 894-902.

Kujala, M. V., Törnqvist, H., Somppi, S., Hänninen, L., Krause, C.M., Vainio, O., Kujala, J., 2013. Reactivity of dogs' brain oscillations to visual stimuli measured with non-invasive electroencephalography. PLoS One 8, 1-8. https://doi.org/10.1371/journal.pone.0061818

Lancel, M., 1993. Relation to Sleep-Wake Behavior in Mammalian Species. Neuropsychobiology $28,154-159$.

Larose, C., Richard-Yris, M.-A., Hausberger, M., Rogers, L., 2006. Laterality of horses associated with emotionality in novel situations. Laterality Asymmetries Body, Brain, Cogn. 11, 355367. https://doi.org/10.1080/13576500600624221

Lesimple, C., 2020. Indicators of horse welfare: State-of-the-art. Animals 10. https://doi.org/10.3390/ani10020294

Lesimple, C., Fureix, C., Menguy, H., Hausberger, M., 2010. Human direct actions may alter animal welfare, a study on horses (Equus caballus). PLoS One 5, e10257. https://doi.org/10.1371/journal.pone.0010257

Lesimple, C., Hausberger, M., 2014. How accurate are we at assessing others' well-being? The example of welfare assessment in horses. Front. Psychol. 5, 21. https://doi.org/10.3389/fpsyg.2014.00021

Lesimple, C., Poissonnet, A., Hausberger, M., 2016. How to keep your horse safe? An epidemiological study about management practices. Appl. Anim. Behav. Sci. 181, 105-114. https://doi.org/10.1016/J.APPLANIM.2016.04.015

Lesimple, C., Reverchon-Billot, L., Galloux, P., Stomp, M., Boichot, L., Coste, C., Henry, S., Hausberger, M., 2020. Free movement: A key for welfare improvement in sport horses? Appl. Anim. Behav. Sci. 225.

Luo, Q., Holroyd, T., Jones, M., Hendler, T., Blair, J., 2007. Neural dynamics for facial threat processing as revealed by gamma band synchronization using MEG. Neuroimage 34, 839847. https://doi.org/10.1016/J.NEUROIMAGE.2006.09.023 
Mason, G., Rushen, J., 2006. Stereotypic animal behaviour : fundamentals and applications to welfare. CABI Pub.

Mason, G.J., 1991. Stereotypies and suffering. Behav. Processes 25, 103-115. https://doi.org/10.1016/0376-6357(91)90013-P

McGreevy, P.D., Cripps, P.J., French, N.P., Green, L.E., Nicol, C.J., 1995. Management factors associated with stereotypic and redirected behaviour in the Thoroughbred horse. Equine Vet. J. 27, 86-91. https://doi.org/10.1111/j.2042-3306.1995.tb03041.x

Meerwijk, E.L., Ford, J.M., Weiss, S.J., 2015. Resting-State EEG Delta Power is Associated with Psychological Pain in Adults with a History of Depression. Biol. Psychol. 105, 106-114.

Mendl, M., Burman, O.H.P., Parker, R.M.A., Paul, E.S., 2009. Cognitive bias as an indicator of animal emotion and welfare: Emerging evidence and underlying mechanisms. Appl. Anim. Behav. Sci. 118, 161-181. https://doi.org/10.1016/J.APPLANIM.2009.02.023

Mills, D.S., 2005a. Repetitive movement problems in the horse, in: The Domestic Horse: The Evolution, Development and Management of Its Behaviour. Cambridge University Press, pp. 212-227.

Mills, D.S., 2005b. Repetitive movement problems in the horse, in: Cambridge university press (Ed.), The Domestic Horse: The Origins, Development, and Management of Its Behaviour. pp. 212-227.

Mormède, P., Andanson, S., Aupérin, B., Beerda, B., Guémené, D., Malmkvist, J., Manteca, X., Manteuffel, G., Prunet, P., van Reenen, C.G., Richard, S., Veissier, I., 2007. Exploration of the hypothalamic-pituitary-adrenal function as a tool to evaluate animal welfare. Physiol. Behav. 92, 317-339. https://doi.org/10.1016/J.PHYSBEH.2006.12.003

Murrell, J., Johnsony, C., White, K., Taylor, P., Haberham, Z., Waterman-Pearson, A., 2003. Changes in the EEG during castration in horses and ponies anaes- thetized with halothane. Vet. Vet. Anaesth. Analg. 30, 46.

Murrell, J., White, K.L., Johnson, C.B., Taylor, P.M., Doherty, T. J., Waterman-Pearson, A.E., 2005. Investigation of the EEG effects of intravenous lidocaine during halothane anaesthesia in ponies. Vet. Anaesth. Analg. 32, 212-221.

Oathes, D.J., Ray, W.J., Yamasaki, A.S., Borkovec, T.D., Castonguay, L.G., Newman, M.G., Nitschke, J., 2008. Worry, generalized anxiety disorder, and emotion: Evidence from the EEG gamma band. Biol. Psychol. 79, 165-170. https://doi.org/10.1016/J.BIOPSYCH0.2008.04.005

Opdam, H., Federico, P., Jackson, G.D., Buchanan, J., Abbott, D.F., Fabinyi, G.C.., Syngeniotis, A., Vosmansky, M., Archer, J.S., Wellard, M.R., Bellomo, R., 2002. A Sheep Model for the Study of Focal Epilepsy with Concurrent Intracranial EEG and Functional MRI. Epilepsia 43, 779787.

Parker, M., Redhead, E.S., Goodwin, D., McBride, S.D., 2008. Impaired instrumental choice in cribbiting horses (Equus caballus). Behav. Brain Res. 191, 137-140. https://doi.org/10.1016/J.BBR.2008.03.009

Paul, E.S., Harding, E.J., Mendl, M., 2005. Measuring emotional processes in animals: the utility of a cognitive approach. Neurosci. Biobehav. Rev. 29, 469-491. https://doi.org/10.1016/J.NEUBIOREV.2005.01.002

Pawluski, J., Jego, P., Henry, S., Bruchet, A., Palme, R., Coste, C., Hausberger, M., 2017. Low plasma cortisol and fecal cortisol metabolite measures as indicators of compromised welfare in domestic horses (Equus caballus). PLoS One 12, e0182257. https://doi.org/10.1371/journal.pone.0182257 
Posner, M., Snyder, C.R., Davidson, B.J., 1980. Attention and the detection of signals. J. Exp. Psychol. Gen. 109, 160-174.

Putman, P., van Peer, J., Maimari, I., van der Werff, S., 2010. EEG theta/beta ratio in relation to fear-modulated response-inhibition, attentional control, and affective traits. Biol. Psychol. 83, 73-78. https://doi.org/10.1016/J.BIOPSYCHO.2009.10.008

Rapin, V., Poncet, P.A., Burger, D., Mermod, C., Hausberger, M., Richard, M.-A., 2007. Mesure de la durée d'attention chez le cheval. Schweiz. Arch. Tierheilkd. 149, 77-83. https://doi.org/10.1024/0036-7281.149.2.77

Rault, J.-L., Truong, S., Hemsworth, L., Le Chevoir, M., Bauquier, S., Lai, A., 2019. Gentle abdominal stroking ('belly rubbing') of pigs by a human reduces EEG total power and increases EEG frequencies. Behav. Brain Res. 374, 111892. https://doi.org/10.1016/j.bbr.2019.04.006

Reddan, M.C., Wager, T.D., 2019. Brain systems at the intersection of chronic pain and selfregulation. Neurosci. Lett. https://doi.org/10.1016/j.neulet.2018.11.047

Rivera, E., Benjamin, S., Nielsen, B., Shelle, J., Zanella, A.J., 2002. Behavioral and physiological responses of horses to initial training: the comparison between pastured versus stalled horses. Appl. Anim. Behav. Sci. 78, 235-352.

Rochais, C., Fureix, C., Lesimple, C., Hausberger, M., 2016a. Lower attention to daily environment: a novel cue for detecting chronic horses' back pain? Sci. Rep. 6, 20117. https://doi.org/10.1038/srep20117

Rochais, C., Henry, S., Fureix, C., Hausberger, M., 2016b. Investigating attentional processes in depressive-like domestic horses (Equus caballus). Behav. Processes 124, 93-96. https://doi.org/10.1016/J.BEPROC.2015.12.010

Rochais, C, Henry, S., Hausberger, M., 2018. "Hay-bags" and "Slow feeders": Testing their impact on horse behaviour and welfare. Appl. Anim. Behav. Sci. 198, 52-59. https://doi.org/10.1016/j.applanim.2017.09.019

Rochais, C., Sébilleau, M., Menoret, M., Oger, M., Henry, S., Hausberger, M., Cousillas, H., 2018. Attentional state and brain processes: state-dependent lateralization of EEG profiles in horses. Sci. Rep. 8, 10153. https://doi.org/10.1038/s41598-018-28334-9

Rodenbeck, A., Binder, R., Geisler, P., Danker-Hopfe, H., Lund, R., Raschke, F., Weeß, H.-G., Schulz, H., 2006. A Review of Sleep EEG Patterns. Part I: A Compilation of Amended Rules for Their Visual Recognition according to Rechtschaffen and Kales. Somnologie 10, 159-175. https://doi.org/10.1111/j.1439-054X.2006.00101.x

Rogers, L.J., 2010. Relevance of brain and behavioural lateralization to animal welfare. Appl. Anim. Behav. Sci. 127, 1-11. https://doi.org/10.1016/J.APPLANIM.2010.06.008

Rushen, J., 1991. Problems associated with the interpretation of physiological data in the assessment of animal welfare. Appl. Anim. Behav. Sci. 28, 381-386. https://doi.org/10.1016/0168-1591(91)90170-3

Sammler, D., Grigutsch, M., Fritz, T., Koelsch, S., 2007. Music and emotion: Electrophysiological correlates of the processing of pleasant and unpleasant music. Psychophysiology 44, 293304. https://doi.org/10.1111/j.1469-8986.2007.00497.x

Sarrias, M.., Martinez, E., Celada, P., Udina, C., Alvarez, E., Artigas, F., 1991. Plasma Free 5HT and Platelet 5HT in Depression: Case-Control Studies and the Effect of Antidepressant Therapy, in: Kynurenine and Serotonin Pathways. Springer, Boston, MA, pp. 653-658.

Schmidt, L.A., Trainor, L.J., 2001. Frontal brain electrical activity (EEG) distinguishes valence and 
intensity of musical emotions. Cogn. Emot. 15, 487-500.

https://doi.org/10.1080/02699930126048

Schutter, D.J.L.G., Van Honk, J., 2005. Electrophysiological ratio markers for the balance between reward and punishment. Cogn. Brain Res. 24, 685-690.

https://doi.org/10.1016/j.cogbrainres.2005.04.002

Schutter, D.J.L.G., Van Honk, J., 2004. Decoupling of midfrontal delta-beta oscillations after testosterone administration. Int. J. Psychophysiol. 53, 71-73.

https://doi.org/10.1016/j.ijpsycho.2003.12.012

Sharot, T., Guitart-Masip, M., Korn, C.W., Chowdhury, R., Dolan, R.J., 2012. How dopamine enhances an optimism bias in humans. Curr. Biol. 22, 1477-1481. https://doi.org/10.1016/j.cub.2012.05.053

Siegel, S., Castellan, J., 1988. Nonparametric statistics for the behavioral sciences, 2nd ed. McGraw-Hill international, New York.

Starkstein, S.E., Petracca, G., Tesón, A., Chemerinski, E., Merello, M., Migliorelli, R., Leiguarda, R., 1996. Catatonia in depression: prevalence, clinical correlates, and validation of a scale. J. Neurol. Neurosurg. Psychiatry 60, 326-32. https://doi.org/10.1136/JNNP.60.3.326

Stockmeier, C.A., 2003. Involvement of serotonin in depression: evidence from postmortem and imaging studies of serotonin receptors and the serotonin transporter. J. psychiatry Res. 37, 357-373.

Stomp, M., Leroux, M., Cellier, M., Henry, S., Lemasson, A., Hausberger, M., 2018. An unexpected acoustic indicator of positive emotions in horses. PLoS One 13, e0197898. https://doi.org/10.1371/journal.pone.0197898

Takahashi, T., Murata, T., Hamada, T., Omori, M., Kosaka, H., Kikuchi, M., Yoshida, H., Wada, Y., 2005. Changes in EEG and autonomic nervous activity during meditation and their association with personality traits. Int. J. Psychophysiol. 55, 199-207. https://doi.org/10.1016/J.IJPSYCHO.2004.07.004

Vallortigara, G., Rogers, L.J., 2005. Survival with an asymmetrical brain: Advantages and disadvantages of cerebral lateralization. Behav. Brain Sci. 28, 575-633.

Visser, E.K., Ellis, A.D., Van Reenen, C.G., 2008. The effect of two different housing conditions on the welfare of young horses stabled for the first time. Appl. Anim. Behav. Sci. 114, 521-533. https://doi.org/10.1016/J.APPLANIM.2008.03.003

Waring, G.H., 2003. Horse behavior. The behavioral traits and adaptations of domestic and wild horses, including ponies. Horse Behav. Behav. Trait. Adapt. Domest. wild horses, Incl. ponies.

Williams, D., Brosnan, R., Fletcher, D., Aleman, M., Holliday, T., Tharp, B., Kass, P., LeCouteur, R., Steffey, E., 2016. Qualitative and quantitative characteristics of the electroencephalogram in normal horses during administration of inhaled anesthesia. J. Vet. Intern. Med. 30, 2893030.

Williams, D.C., Aleman, M., Holliday, T.A., Fletcher, D.J., Tharp, B., Kass, P.H., Steffey, E.P., LeCouteur, R.A., 2008. Qualitative and Quantitative Characteristics of the Electroencephalogram in Normal Horses during Spontaneous Drowsiness and Sleep. J. Vet. Intern. Med. 22, 630-638. https://doi.org/10.1111/j.1939-1676.2008.0096.x

Williams, D.C., Aleman, M., Tharp, B., Fletcher, D.J., Kass, P.H., Steffey, E.P., Lecouteur, R.A., Holliday, T.A., 2012. Qualitative and Quantitative Characteristics of the Electroencephalogram in Normal Horses After Sedation. J. Vet. Intern. Med. 26, 645-653. 
https://doi.org/10.1111/j.1939-1676.2012.00921.x

Williams, D.C., Aleman, M.R., Brosnan, R.J., Fletcher, D.J., Holliday, T.A., Tharp, B., Kass, P.H., Steffey, E.P., Lecouteur, R.A., 2016. Electroencephalogram of Healthy Horses During Inhaled Anesthesia. J. Vet. Intern. Med. 30, 304-308. https://doi.org/10.1111/jvim.13613 

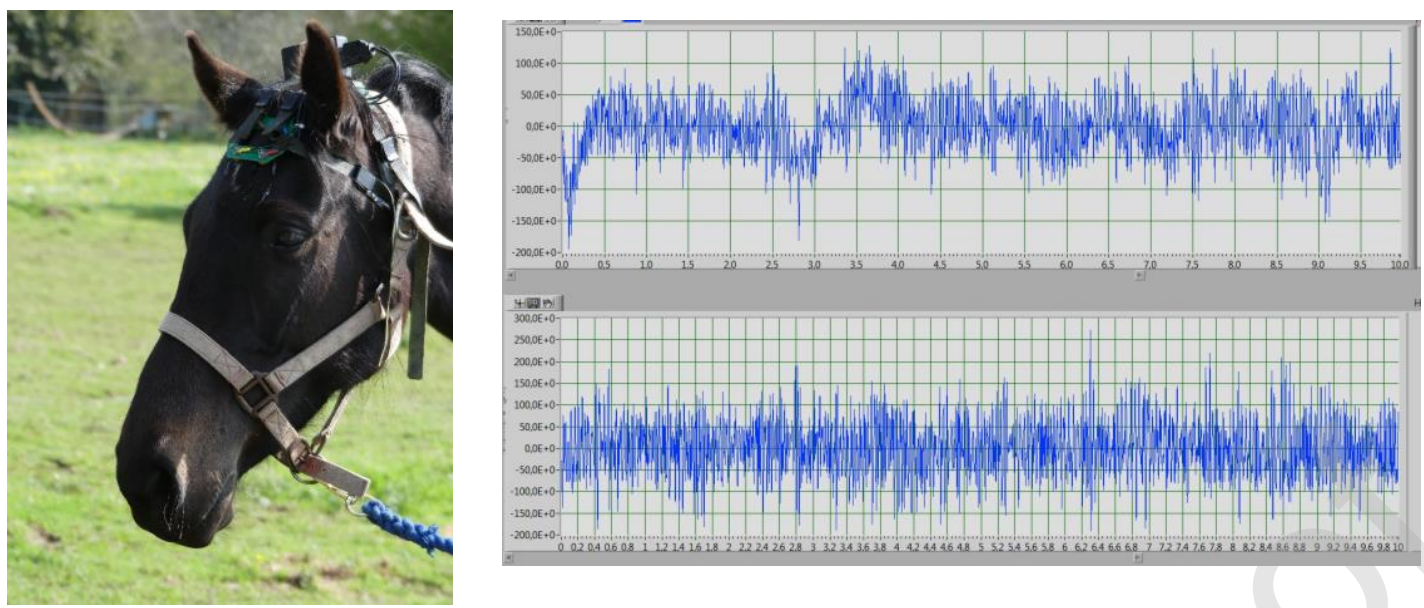

Fig.1: (left) EEG headset used in the present study. (right) Example of $10 \mathrm{~s}$ electroencephalography (EEG) recordings obtained with the EEG headset.
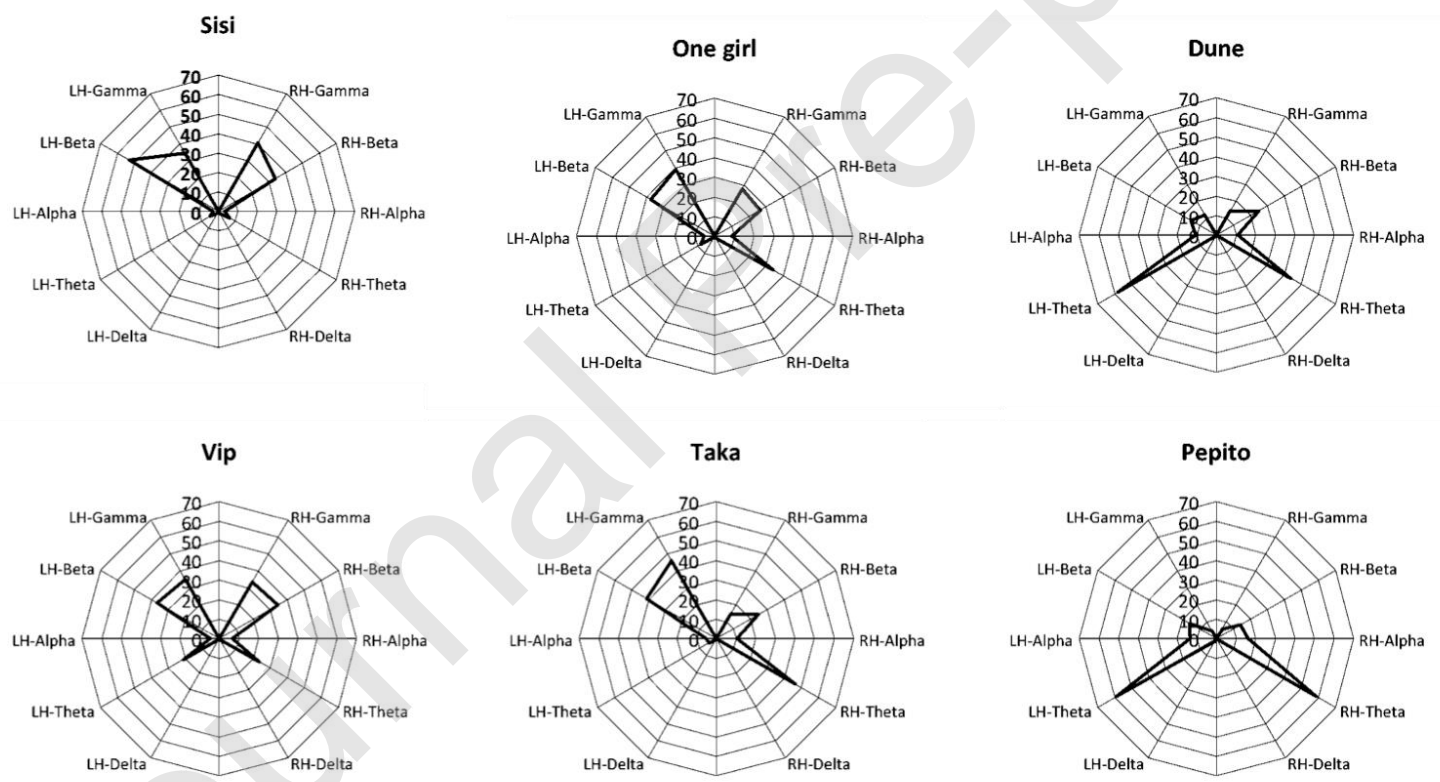

Fig.2: Examples of 6 individual quantitative EEG power profiles. Each radius represents the median proportion of each wave frequency in each hemisphere. For example, Sisi shows in both hemispheres around $90 \%$ beta and gamma waves and almost no slow waves (i.e. theta- delta), while One Girl shows more than $40 \%$ theta and $30 \%$ beta and gamma respectively in the right hemisphere and almost only beta and gamma waves in the left hemisphere. 


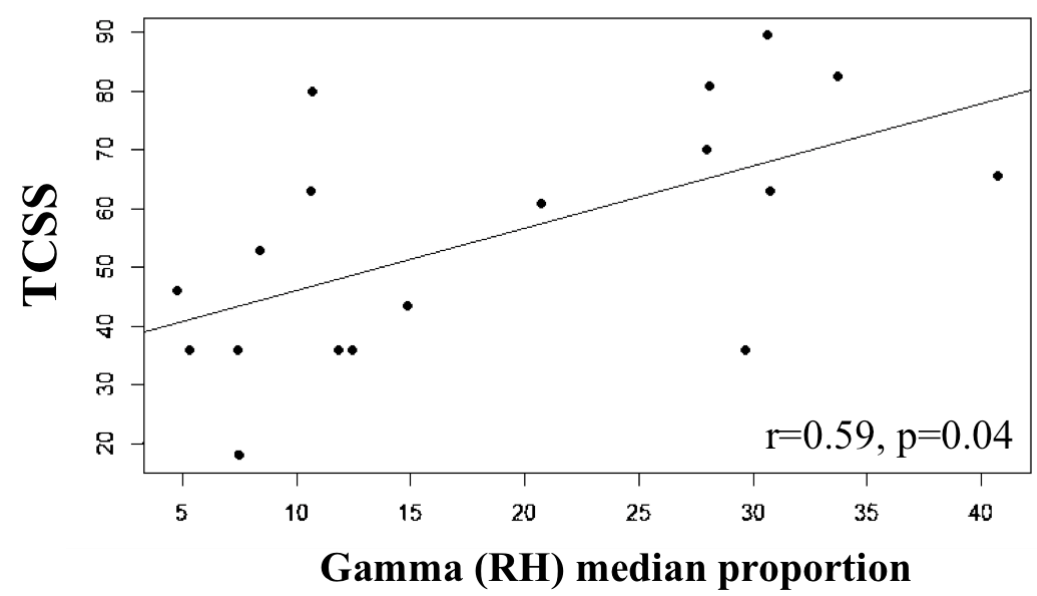

Fig. 3: Correlation between the total chronic stress score and the proportion of gamma waves in the right hemisphere.

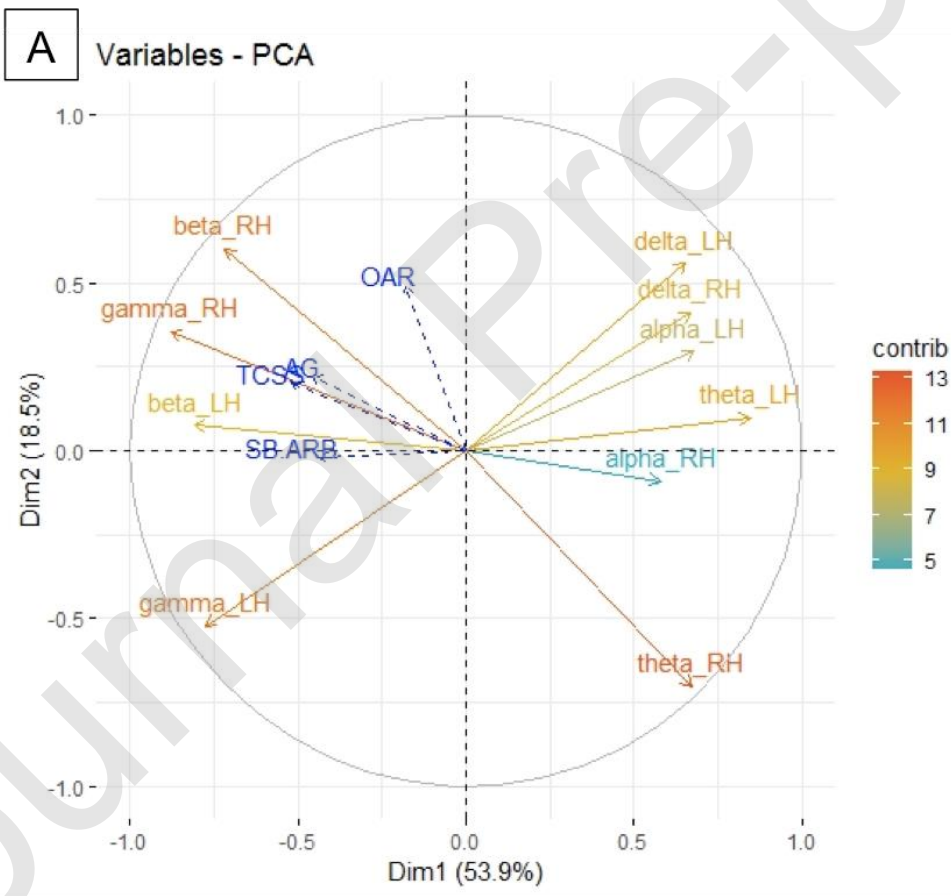



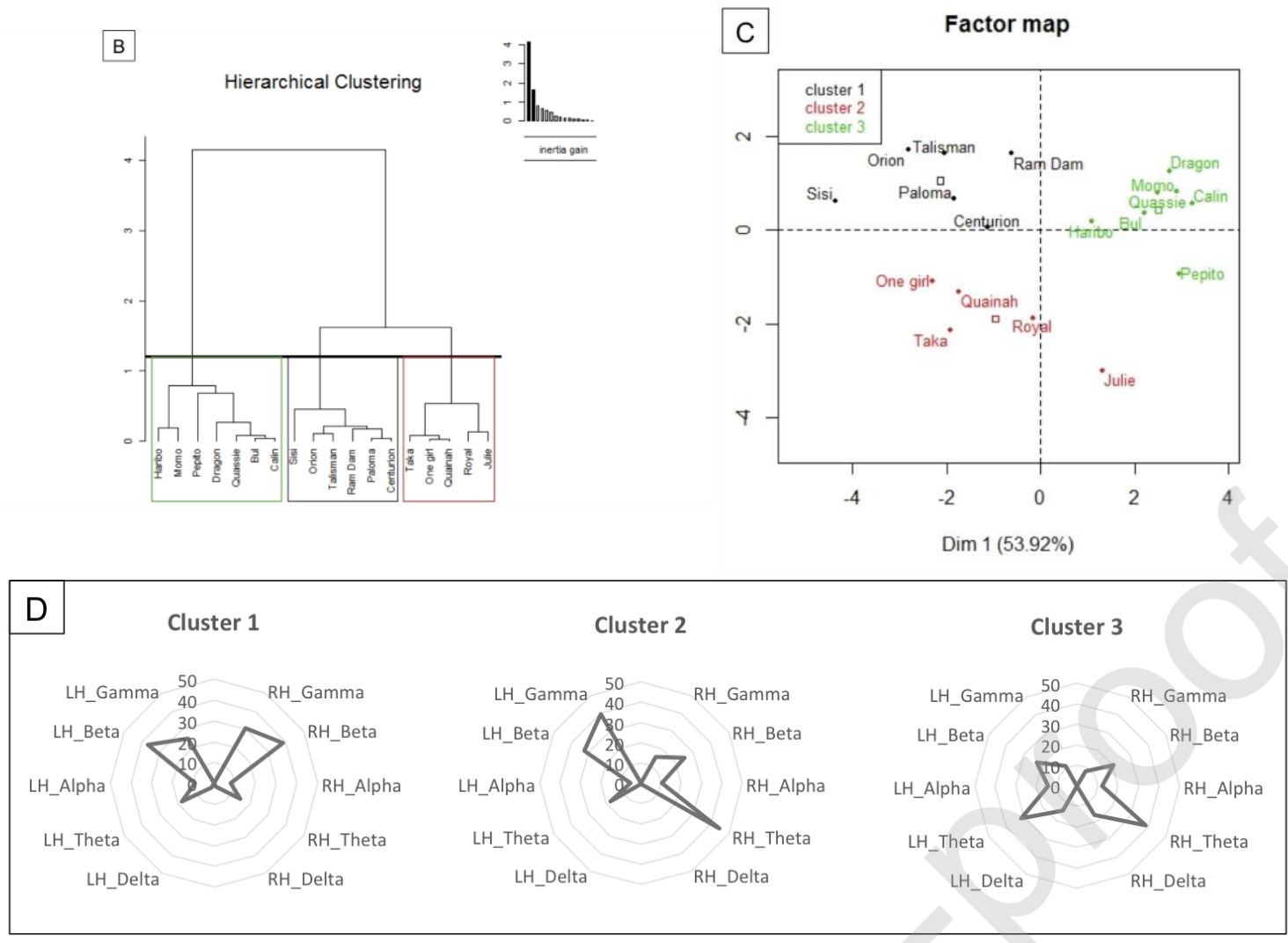

Fig.4: Cluster analysis of individual EEG profiles. (A) Variables factor map obtained from the Principal Component Analysis. LH (left hemisphere), RH (right hemisphere), OAR (ears backwards), AG (aggressive behaviours towards human), SB/ARB (stereotypic behaviours/ abnormal repetitive behaviours) TCSS (total chronic stress score). (B) Hierarchical cluster analysis. (C) Factor map obtained from the Principal Component Analysis illustrating the distribution of horses according to their EEG recordings. (D) Example of a representative individual EEG profile of horses from the different clusters recorded in a context of quiet standing. Radar plots of the three profiles defined from the hierarchical cluster analysis (Johnson, 1967). Each radius represents the median proportion of each wave frequency in each hemisphere. 

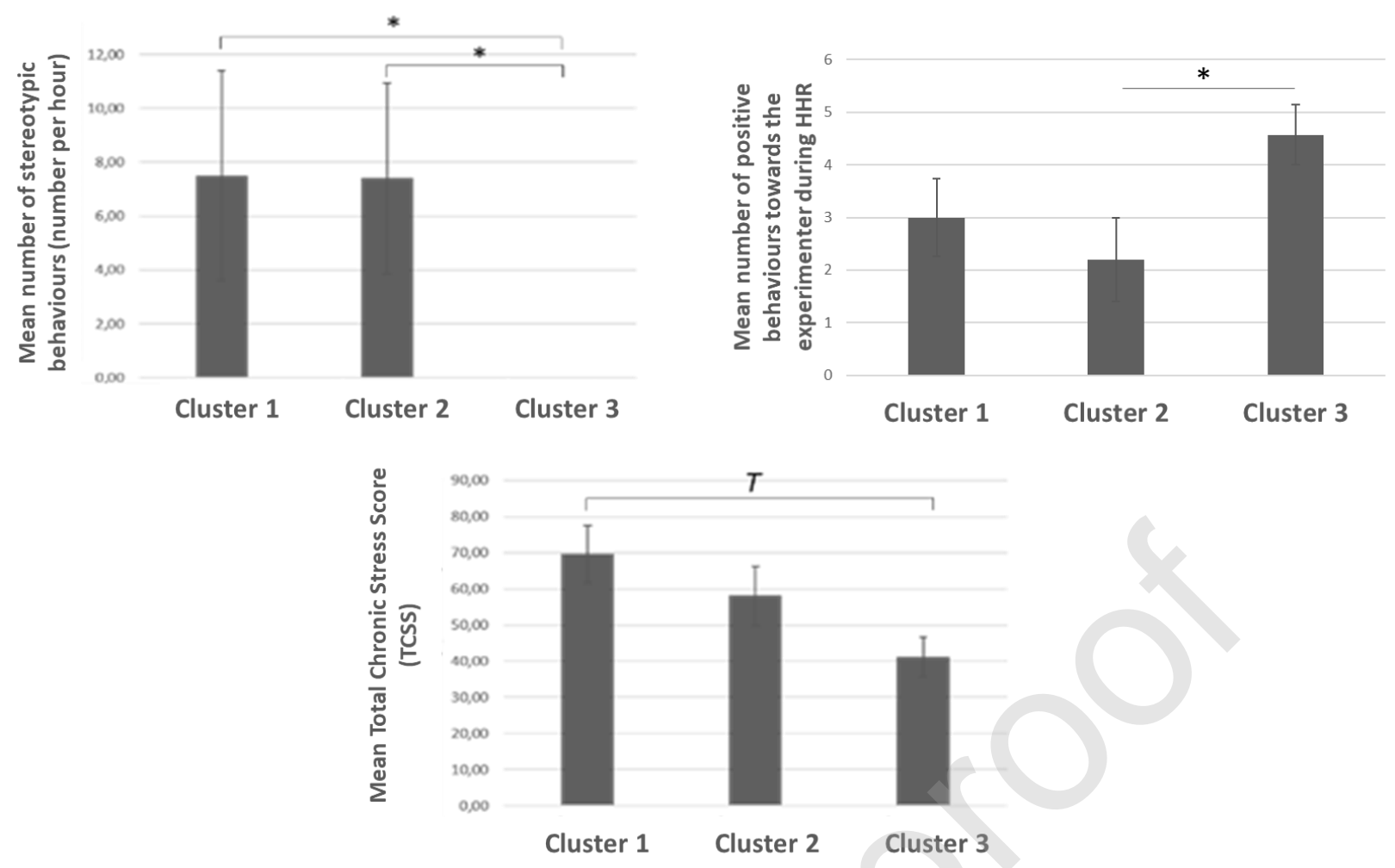

Fig. 5: Welfare indicators according to EEG clusters. ${ }^{*} \mathrm{p}<0.05, T \mathrm{p}=0.07$.

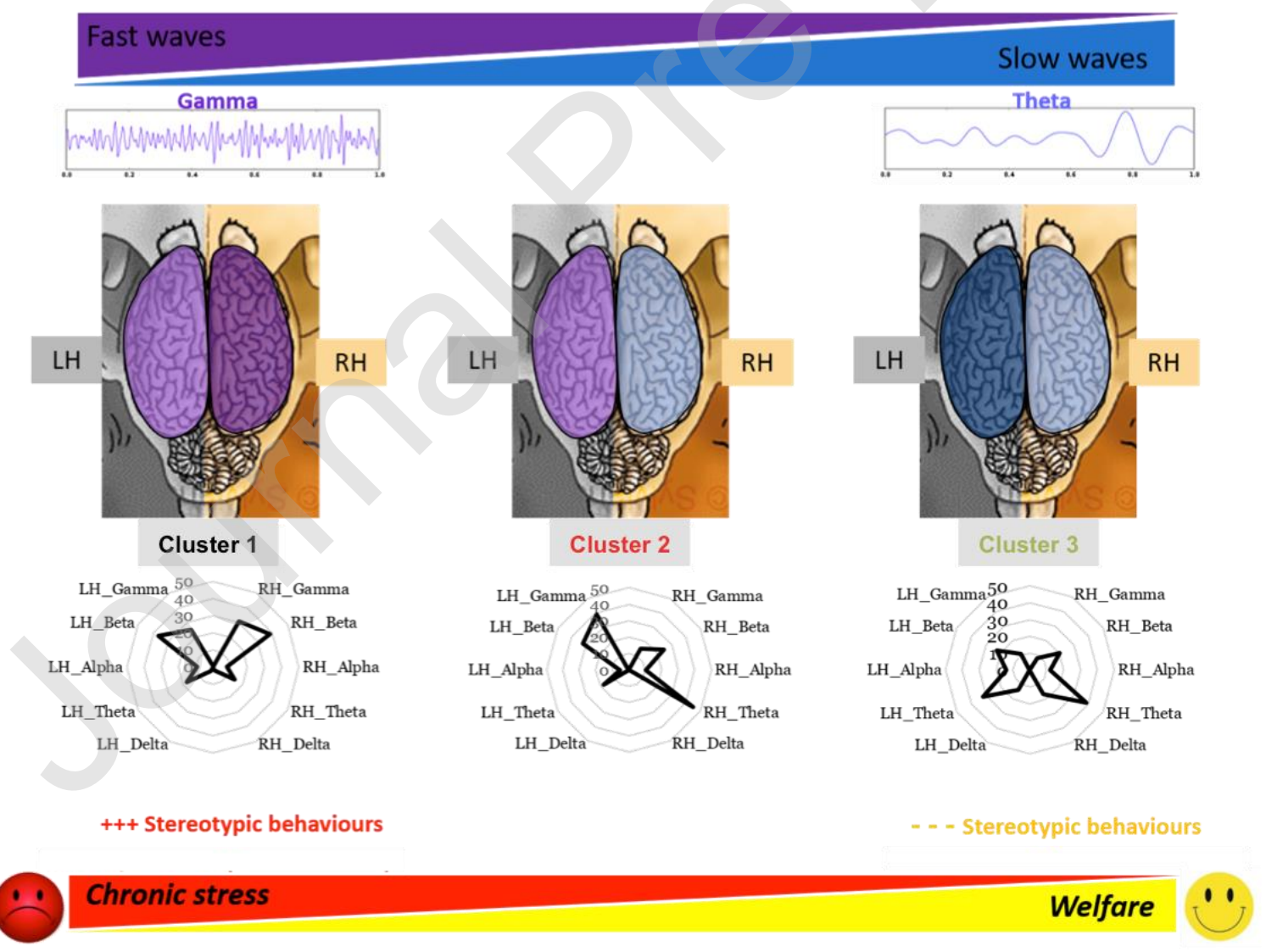

Fig.6: EEG power spectrum profiles and welfare parameters of the three different clusters, LH (left hemisphere), RH (right hemisphere). 
Table 1: Characteristics of the individuals involved in the study.

\begin{tabular}{|l|l|l|l|l|l|l|l|}
\hline Individual & Population & Sex & Age & Individual & Population & Sex & Age \\
\hline Bul & Leisure & Gelding & 5 & Centurion & Restricted & Gelding & 9 \\
\hline Calin & Leisure & Stallion & 4 & Orion & Restricted & Gelding & 14 \\
\hline Dragon & Leisure & Stallion & 3 & Ram Dam & Restricted & Gelding & 11 \\
\hline Momo & Leisure & Gelding & 16 & Royal & Restricted & Gelding & 11 \\
\hline Pepito & Leisure & Gelding & 12 & Talisman & Restricted & Gelding & 9 \\
\hline Haribo & Leisure & Gelding & 21 & One Girl & Restricted & Mare & 14 \\
\hline Julie & Leisure & Mare & 19 & Quaïnah & Restricted & Mare & 12 \\
\hline Quassie & Leisure & Mare & 12 & Sisi & Restricted & Mare & 10 \\
\hline Paloma & Leisure & Mare & 15 & Taka & Restricted & Mare & 12 \\
\hline
\end{tabular}

Table 2: Type, classification and description of recorded abnormal repetitive behaviours.

SB: stereotypic behavior; ARB: abnormal repetitive behaviour. For ease of reading both categories have been grouped for the rest of the manuscript as "stereotypic behaviours"

\begin{tabular}{|l|l|l|}
\hline SB/ARB behavioural description & Type & Classification \\
\hline head tossing / nodding/shaking: vertical movements of head and neck & motor & SB \\
\hline striking repeteadly with forelimb: horse hits the door or wall with one of its forelegs & motor & SB \\
\hline box walking: repetitive tracing of a route within the stable & motor & SB \\
\hline cribbing / wind sucking: the horse grasps a fixed object with its incisors (cribbing), & oral & SB \\
\hline pulls backwards and draws air into its oesophagus (both) & & \\
\hline lip shivering : shivering of the lower lip & motor & ARB \\
\hline repetitive displacement of the saddle support on the stall door & motor & ARB \\
\hline
\end{tabular}




\begin{tabular}{|l|l|l|}
\hline tongue movements: repetitive movements of tongue, inside or outside its mouth & oral & ARB \\
\hline repetitive biting: biting a given object in its environment & oral & ARB \\
\hline repetitive licking: licking a given object in its environment & oral & ARB \\
\hline
\end{tabular}

